\title{
Impact of Mentoring on Nursing and Midwifery Educators and Students: An Integrative
}

\author{
Article by Elizabeth Namukombe Ekong ${ }^{1}$, Sun J. Carolyne ${ }^{2}$, \\ ${ }^{1}$ PhD, Uganda Christian University, Uganda \\ ${ }^{2}$ Sloan Kettering Institute \\ E-mail: ekongelizabeth@yahoo.com
}

\begin{abstract}
Background: Academic staff shortages exist in training institutions within the developed and developing world. Mentoring is thought to enhance teachers' competencies, strengthen social abilities, and promote learning and career development; however, not much is known about mentoring in developing countries and its impact on nursing academia. The aim of this literature review was to explore existing evidence on the impact of mentoring on nurse and midwifery teaching competencies and students' learning and social abilities, and the pre-requisites for establishing an effective mentoring program.

Methodology: A comprehensive literature search was performed using HINARI, PubMed, SAGE, WILEY, Science direct, Google scholar, and Google search. Hand searching was too done through bibliographies to identify related articles. Results were screened to select studies that reported benefits and challenges of mentoring to nurse and midwifery educators, student nurses and midwives, and successful mentoring programs. After screening, a total of 15 articles met the inclusion criteria and were reviewed and analysed.

Results: Senior faculty mentoring junior faculty provides or enhances accomplishments of some nurse educator core competencies, provides opportunities to develop teaching knowledge base, and promotes exposure to required resources for growth in the teaching career. It further stimulates personal and social growth. Mentored student nurses and midwives experience reduced anxiety, and mentoring provides a supportive learning environment and increased self-awareness of one's own values and beliefs, confidence, maturity and responsibility. Lack of time, dual responsibility, heavy workload, personality, and attitude may negatively impact the mentoring process. An effective mentoring program requires a relevant mentoring model and clear definitions of its context, structure, and goals.
\end{abstract}

Conclusion: Mentoring has the potential to strengthen teaching competencies as well as students' learning and professional growth.

Keywords: Effective Mentoring program, Impact of mentoring, Midwifery educators, Nurse Educators, nursing education, social abilities, student midwives, student nurses, teaching competencies

\section{Background}

Staff shortages in nursing academia continue to be a challenge both in developed and developing countries (Norwell, White, Marklas, \& Norris, 2015). The problem has been attributed to: lack of nurse educators to be recruited in nurse training institutions; lack of enthusiasm by registered nurses to pursue nursing education as a career path; discrepancies in remuneration; and few registered nurses with sufficient education to meet university standards for employment (Nowell, White, Mrklas, \& Norris, 2015). Nurse and midwifery educators should identify or develop models or approaches that can strengthen faculty relationships, enhance new nurse educators' teaching capabilities, and attract them into nursing education, academics and research (NLN, 2006).

Mentoring is one of the models associated with bridging the shortage of academic staffing by reducing the effects of increased workload, stress, and burnout with subsequent staff turnover; and enhancing motivation, growth, and self-esteem among new faculty nurses with the subsequent outcome of job satisfaction and retention (Sawatzky and Enns, 2009; Block, Claffey, Korow, 
Mccaffrey, \& Services, 2005). The mentoring relationship builds an individual's communication and people skills as well as personal development, including how to demonstrate equality and deal with diversity (Scotland, 2007).

The concept of mentoring has been explored in different ways to provide evidence on its role in nursing education, practice, leadership, and administration. Concept analysis was conducted by Hodgson and Scanlan (2013) in relation to nursing leadership. The analysis provided a clear understanding of the definition of mentoring, its use, characteristics, related terms, and defining attributes and explained through clear examples of borderline, related, and contrary cases. The analysis also outlined antecedents (the pre-requisites to mentoring) (Metcalfe, 2010) and results of mentoring, which included job satisfaction, staff retention, empowerment, motivation and professional development (Sawatzky and Enns, 2009; Block, et al, 2005).

Other sources of evidence have been sought through systematic literature reviews to establish the effectiveness and application of mentorship programs for recently registered nurses (Chen and Lou, 2014) and mentorship programs in nursing academia (Nowell, Norris, Mrklas and White, 2017). The systematic reviews found were in academic medicine and education (Kashiwagi, Varkey \& Cook, 2013; Pi-Jen Lin, 2007). In summary, the literature on the importance of mentoring is scarce, and there is an important gap in knowledge to be filled with an integrative review on how mentoring enhances the teacher's competencies. Therefore, this integrative approach was undertaken to seek existing evidence on the impact of mentoring on nurse and midwifery teaching competencies and students' learning abilities, and the pre-requisites for establishing an effective mentoring program. The aim was that the findings would inform best practices for the integration of mentoring into nursing education to strengthen teaching and learning abilities.

\section{Significance to nursing}

Concrete knowledge of the concept of mentoring is key to strengthening a working relationship among nurses and midwives in all sectors: practice, education, leadership and research (Sawatzky and Enns, 2009); (Block et al., 2005). Established evidence on the impact of mentoring on a nurse's and midwife's teaching competencies navigates into possibilities of introducing a mentorship program in an educational institution inclusive of nursing (RCN, 2015). New innovations require evidence-based guidelines. Evidence on pre-requisites for an effective mentoring program would enhance the implementation process of the desired mentoring model in an institution.

\section{Methodology}

A comprehensive literature search was conducted using HINARI, PubMed, SAGE Publications Wiley online library, and Science Direct online databases. Hand search was also done using biographies of retrieved articles. Table 1 is a summary of the databases and other sources used.

Table 1. The search terms and databases and other sources used

\begin{tabular}{|l|l|l|}
\hline Search terms & $\begin{array}{l}\text { Databases and other } \\
\text { sources }\end{array}$ & $\begin{array}{l}\text { Articles retrieved } \\
\text { for screening }\end{array}$ \\
\hline Mentoring and nursing, & HINARI & 0 \\
\hline Mentoring and midwifery & Pub Med-Oxford Journal & 4 \\
\hline $\begin{array}{l}\text { Mentoring and nursing } \\
\text { education }\end{array}$ & SAGE & 20 \\
\hline Impact of mentoring on faculty & Wiley Online Library & 15 \\
\hline $\begin{array}{l}\text { Mentoring and student } \\
\text { nurses/midwives }\end{array}$ & Science Direct & 18 \\
\hline $\begin{array}{l}\text { Effective Mentoring programs } \\
\text { Mentoring and nursing, }\end{array}$ & Google Search & 56 \\
\hline $\begin{array}{l}\text { Mentorship, nursing and } \\
\text { midwifery students }\end{array}$ & Google Scholar & 13 \\
\hline Total articles to be screened & & 13 \\
\hline
\end{tabular}


During the screening, inclusion criteria included studies or reviews published from 2000 to 2017, and included information on the impact or benefits and challenges of mentoring to nurse and midwifery educators or teacher's competencies, and nursing and midwifery students. Additionally, articles or papers that described successful mentoring models and frameworks were included. Only articles written in English language were reviewed. Figure 1 below summarises the identification and screening process.

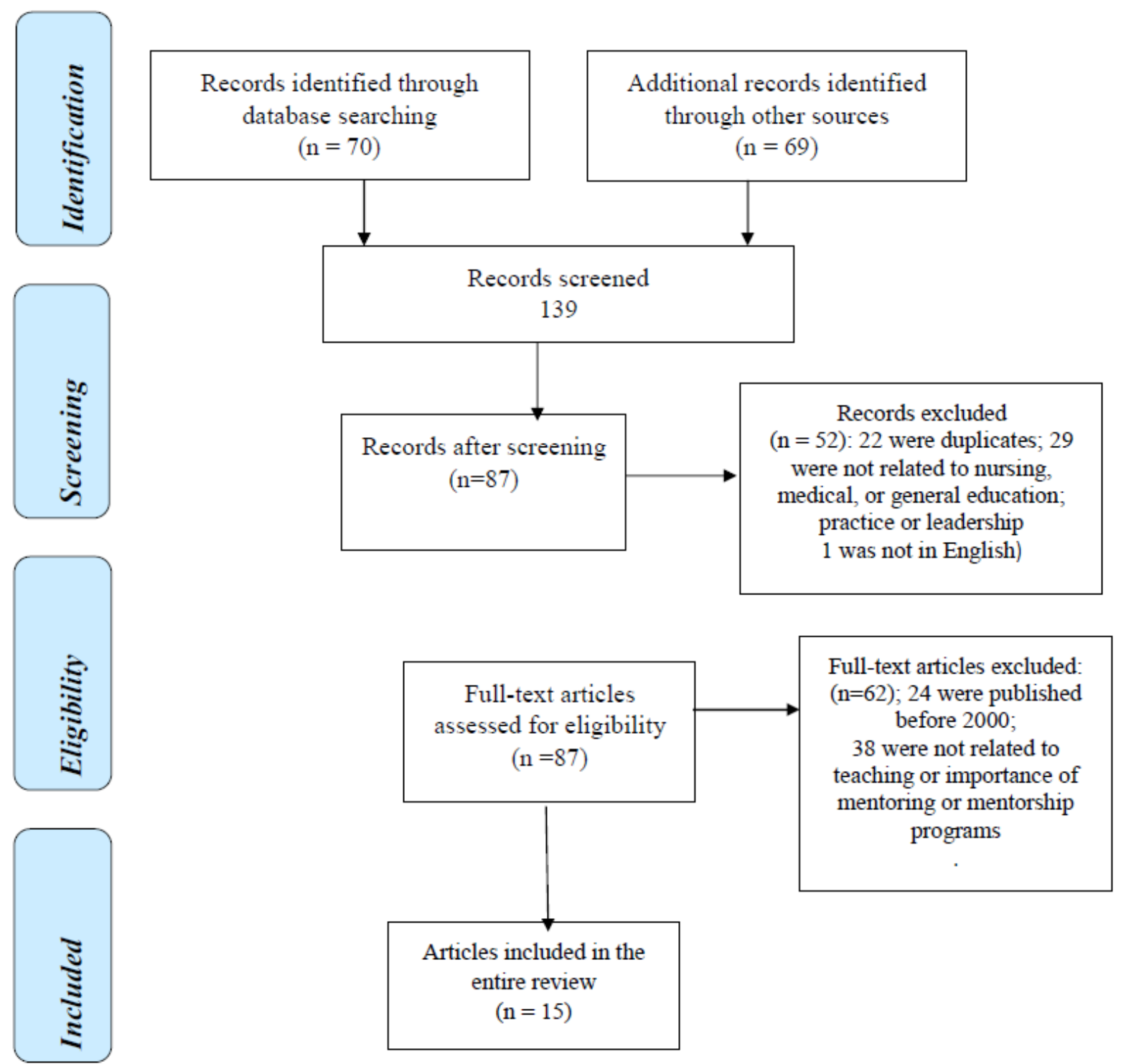

Figure 1. Identification, screening, inclusion and exclusion criteria

Articles were reviewed to answer the stated questions: What is the impact of mentoring on nurse and midwifery educator's teaching competencies, their social relationships, and student nurses' learning? What are the pre-requisites for establishing an effective mentoring program? Since this was an integrative review of literature, the search was not limited to nursing but extended to other disciplines like medicine, psychology, education in general, and leadership and management

A matrix was completed to analyse the results (Table 2). As each article was reviewed and entered in a matrix, key findings were generated under the following headings: impact of mentoring on nurse and midwifery educator's teaching competencies, impact of mentoring on nurse and midwifery educator's social relationships and student nurses' learning, and requirements for an effective mentoring program. 


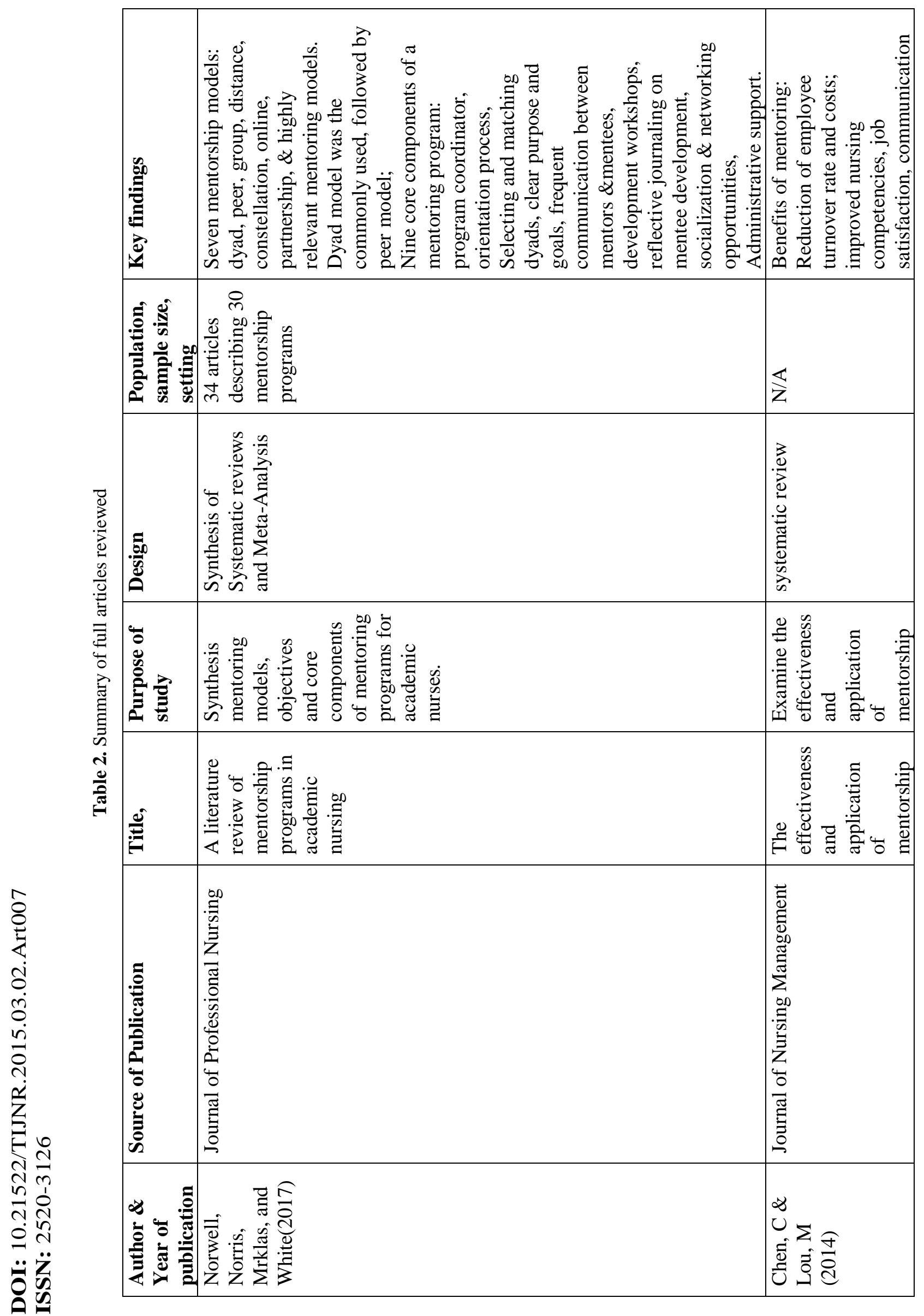




\begin{tabular}{|c|c|c|c|}
\hline 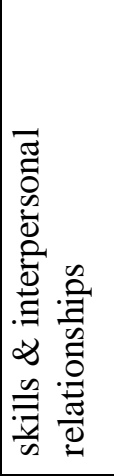 & 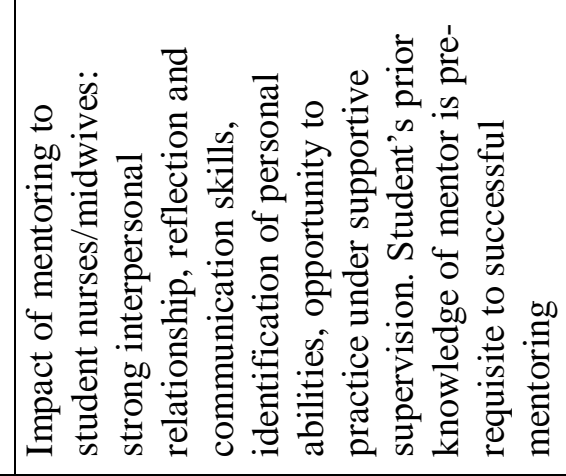 & 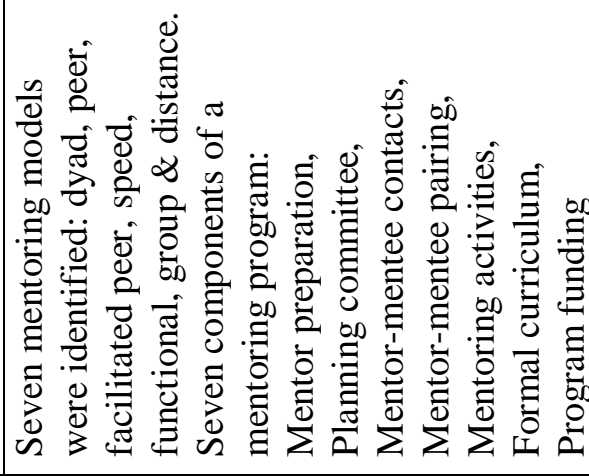 & 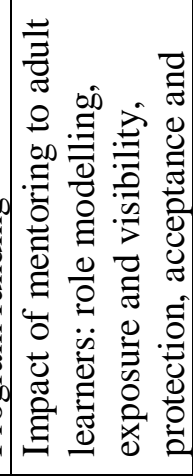 \\
\hline & 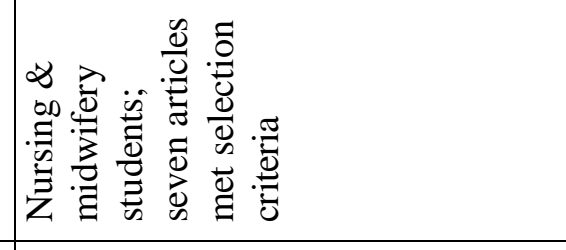 & 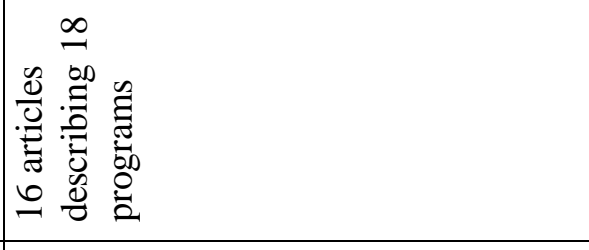 & $\mathbb{z}$ \\
\hline & 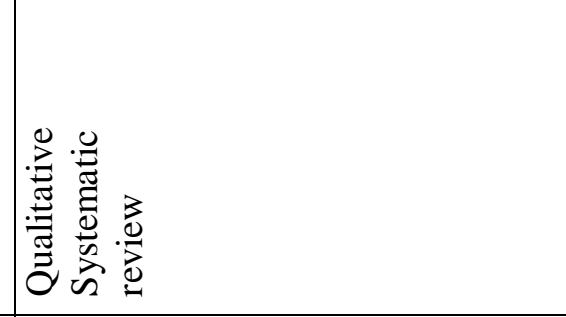 & 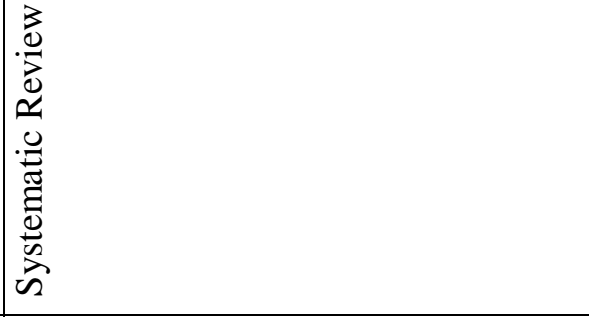 & 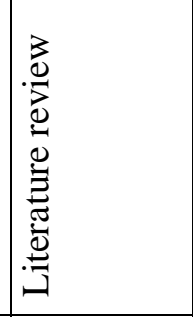 \\
\hline & 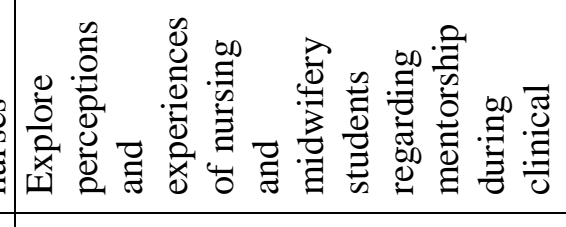 & 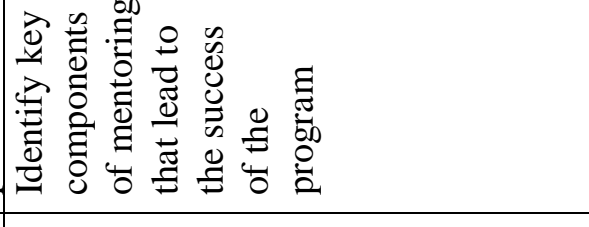 & 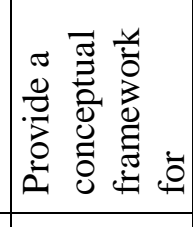 \\
\hline 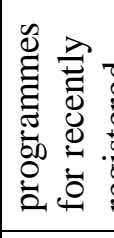 & 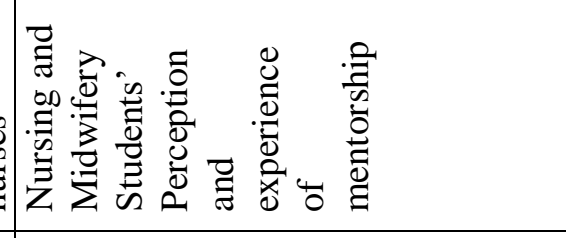 & 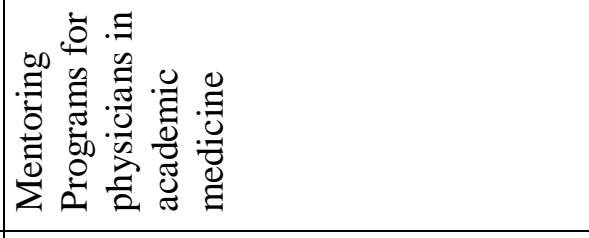 & 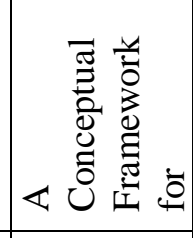 \\
\hline & 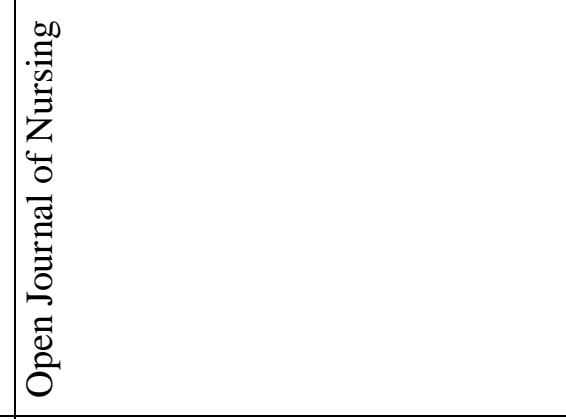 & 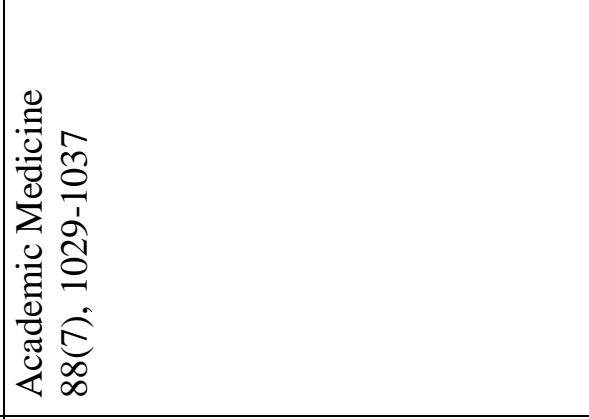 & 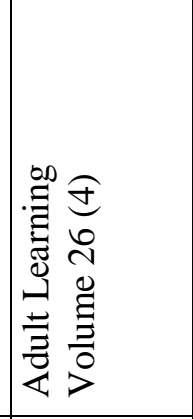 \\
\hline & 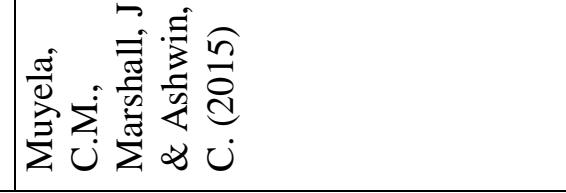 & 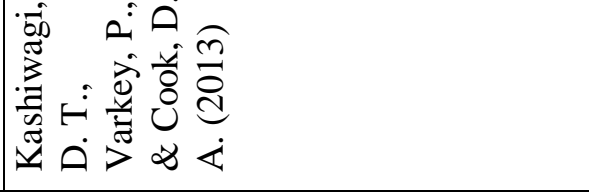 & 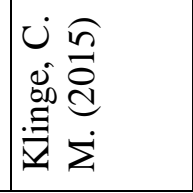 \\
\hline
\end{tabular}




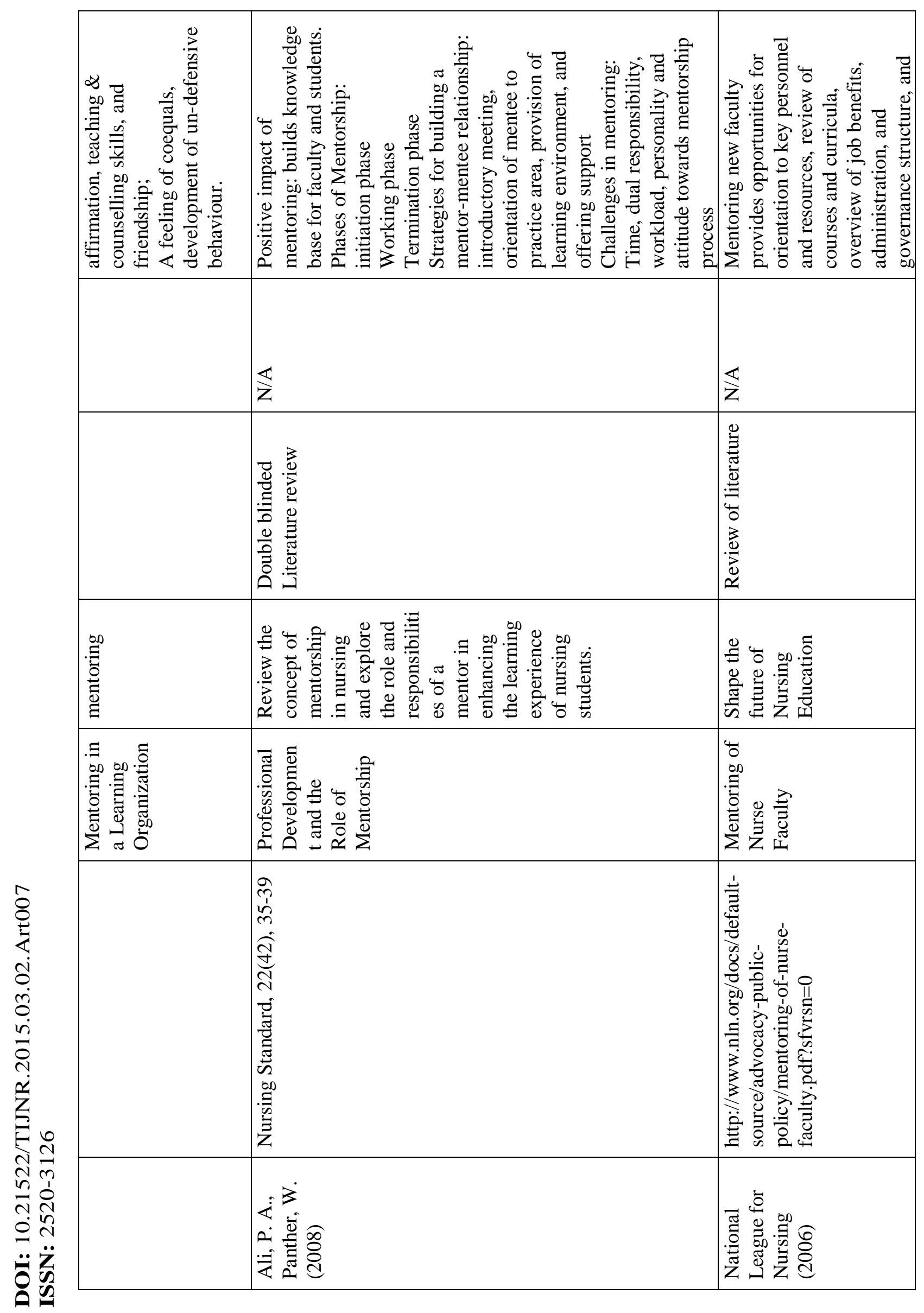




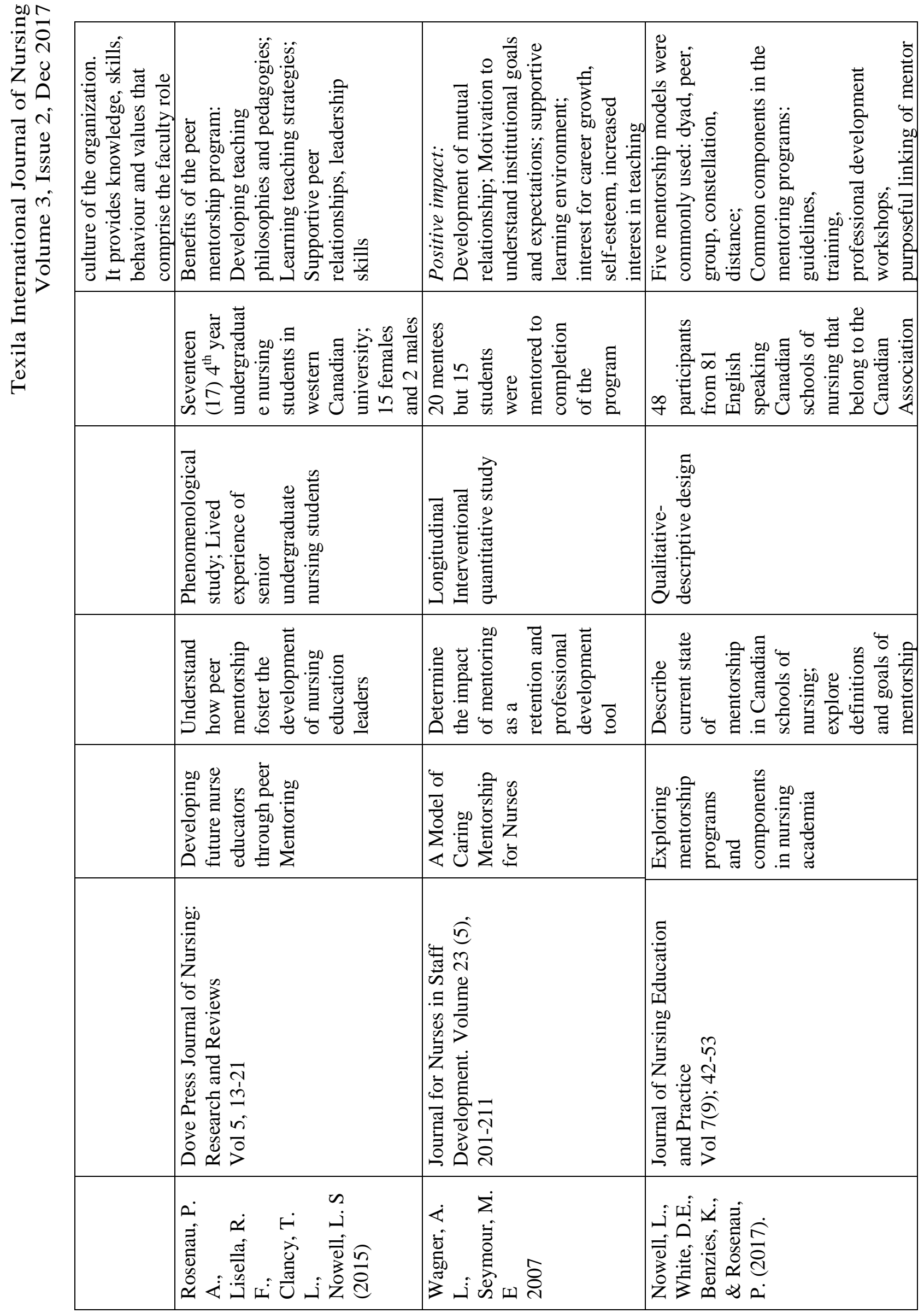




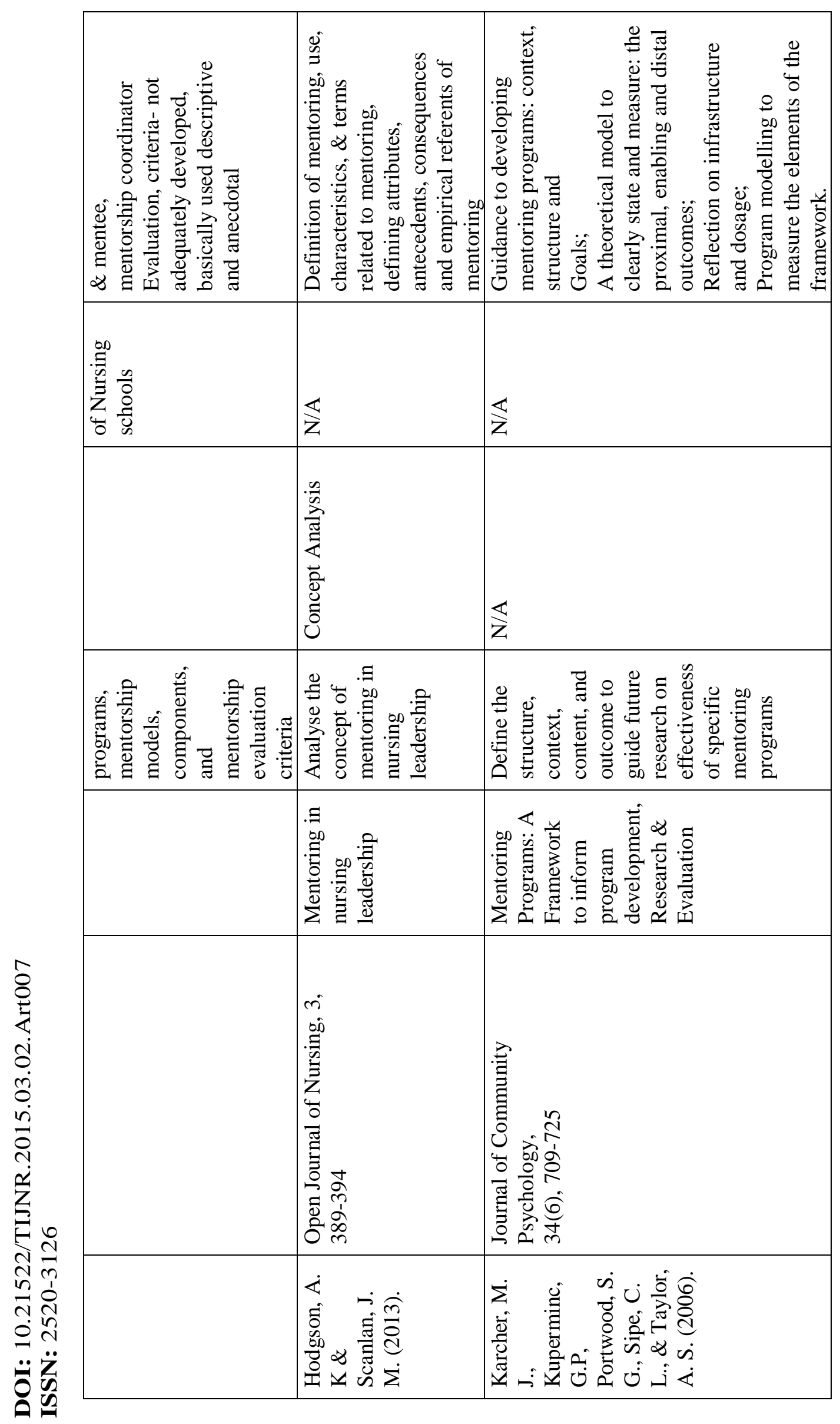




\begin{tabular}{|c|c|c|}
\hline 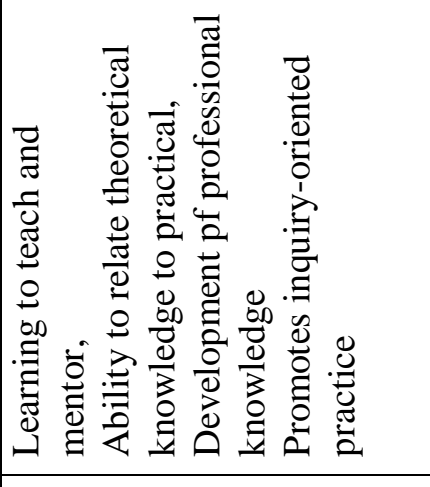 & 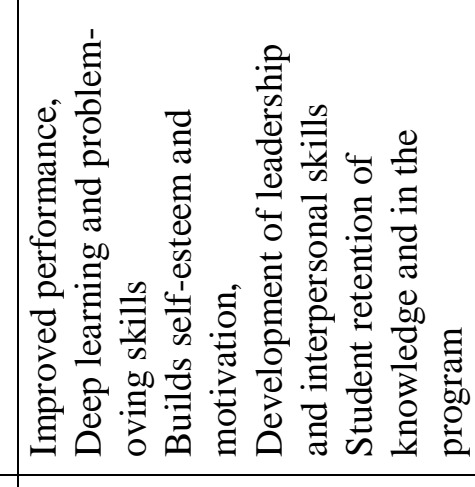 & 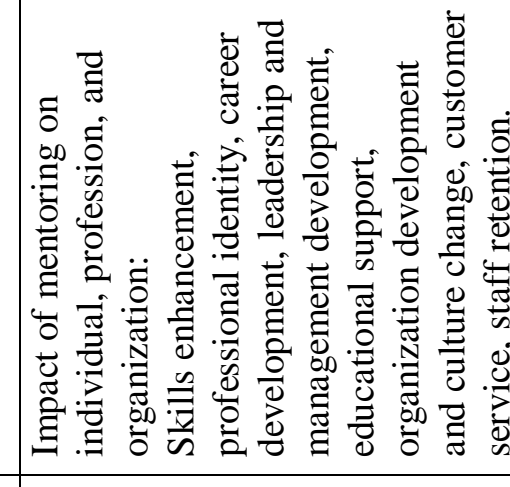 \\
\hline 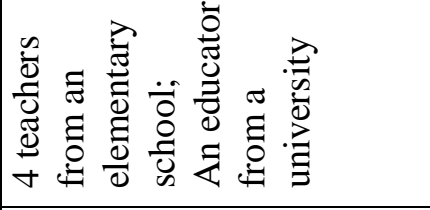 & $\frac{\mathbb{z}}{\mathbf{z}}$ & $\mathbb{z}$ \\
\hline & 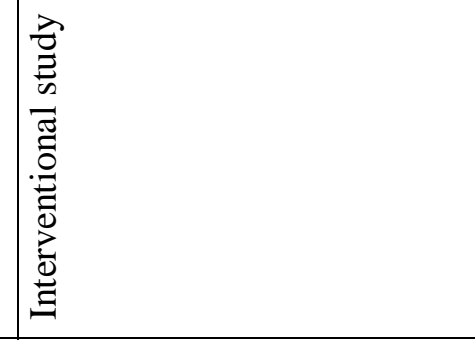 & 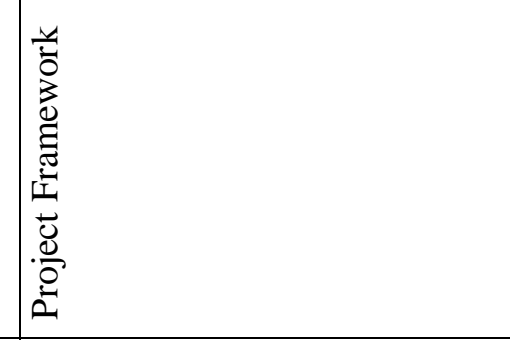 \\
\hline 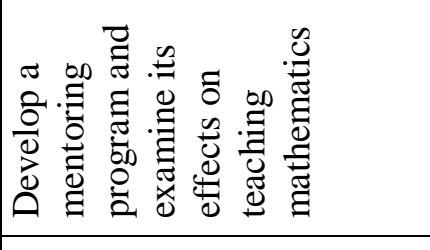 & 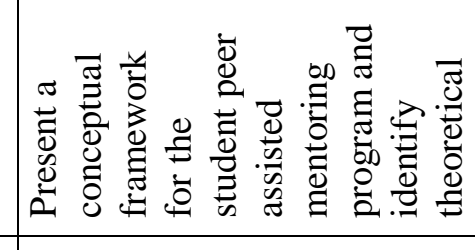 & 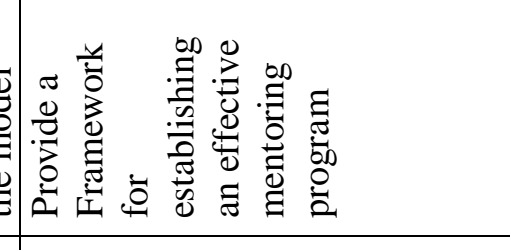 \\
\hline 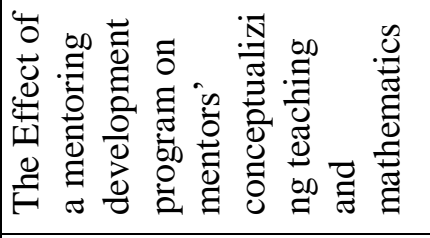 & 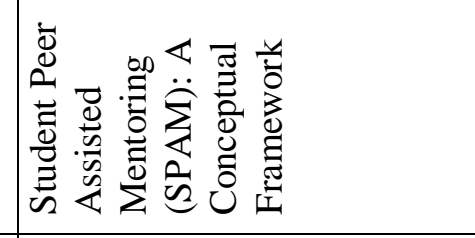 & 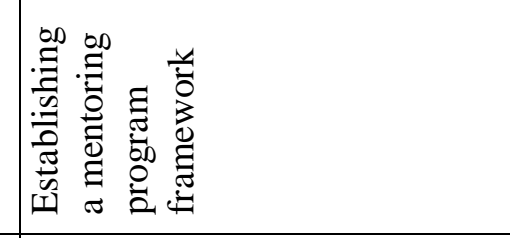 \\
\hline 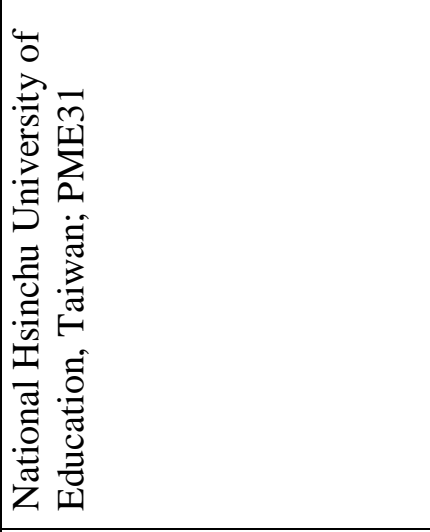 & 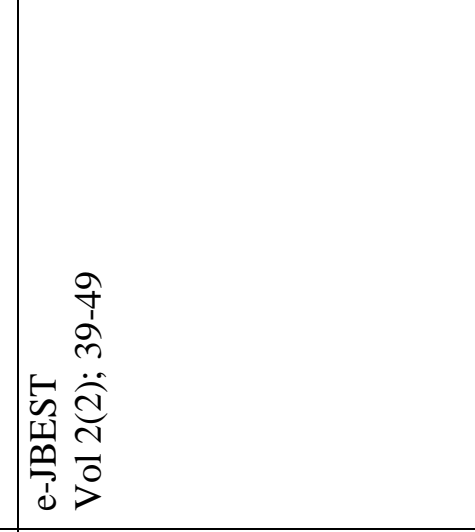 & 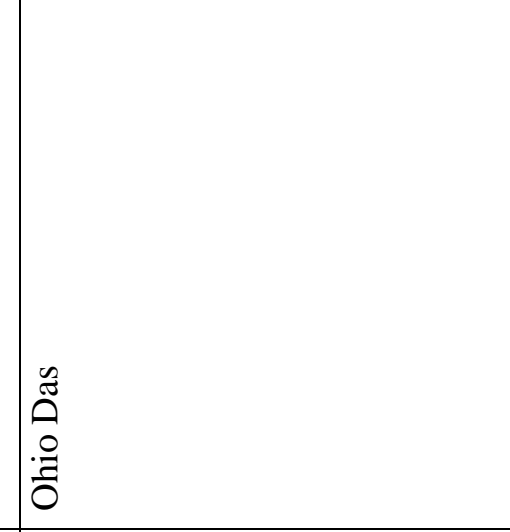 \\
\hline : & 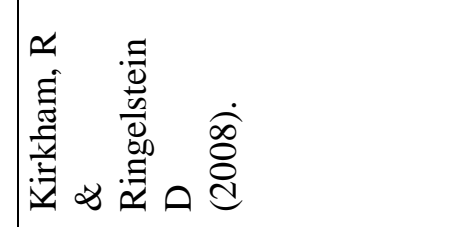 & 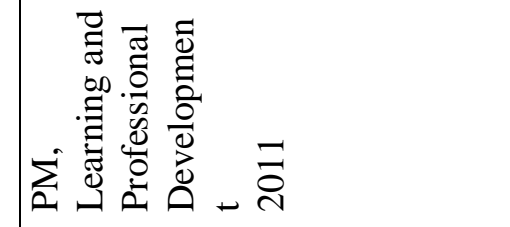 \\
\hline
\end{tabular}




\section{Results}

The search resulted in 139 articles; 22 duplicates were removed (Figure 1). The remaining 117 were screened by title and abstract, 30 were excluded because they did not meet the inclusion criteria. The full text was reviewed in the 87 articles remaining; 24 were excluded because they were published before 2000 , and 8 were excluded because they were not related to teaching or importance of mentoring or mentorship programs, resulting in 15 studies included in the review and entered into the summary matrix (Table 2).

The key thematic statements formulated after analysis included: educator competence development, student learning enhancement, and lastly, personal and social development. The subthemes under each thematic statement are outlined in table 3. On the whole, the general findings are presented following the stated specific objectives

\section{Importance of mentoring}

According to Ali \& Panther (2008), mentoring prepares individuals to develop technical psychomotor, interpersonal, and communication skills; put theory into practice in order to develop a professional identity; and enhances practical experience through support, guidance, and supervision. Mentoring is further associated with a trusting relationship, promoting stability, providing encouragement and hope, and facilitating positive self-efficacy for the student learner (Rosenau, Lisella, Clancy, \& Nowell, 2015).

\section{Impact of mentoring on nurse and midwifery educator's teaching competencies}

Mentoring was found to have both a positive and negative impact (Muleya, Marshall, and Ashwin, 2015; Ali \& Panther, 2008; Lin, 2007); however, the positive impact outweighs the negative impact. It was also noted that the negative impact can be overcome with prior recommended preparation for the mentoring program. On the whole, mentoring was found to increase participants' interest in teaching, self-esteem, and confidence. It also renewed their interest for career growth (Wagner and Seymour, 2007; Rosenau et al, 2015) (Table 3).

Table 3. Thematic statements and their sub-themes

\begin{tabular}{|c|c|c|}
\hline $\begin{array}{l}\text { Educator competence } \\
\text { development }\end{array}$ & $\begin{array}{l}\text { Student Learning } \\
\text { Enhancement }\end{array}$ & $\begin{array}{l}\text { Personal, career, \& social } \\
\text { development }\end{array}$ \\
\hline $\begin{array}{l}\text { Establishment of foundational } \\
\text { teaching skills (philosophies, } \\
\text { pedagogies) with defined roles } \\
\text { and responsibilities of nurse } \\
\text { educators (nurse educator } \\
\text { competencies } 1,2,3,5,6 \& 7 \text { ); } \\
\text { Development of course and } \\
\text { curriculum review skills } \\
\text { Inspiration for teaching } \\
\text { throughout career; } \\
\text { Motivation to understand } \\
\text { institutional goals and } \\
\text { expectations; } \\
\text { Increased interest in teaching; } \\
\text { Being mindful of learners; } \\
\text { Ability to identify teaching } \\
\text { methods that suit student } \\
\text { learning; } \\
\text { Ability to provide timely and } \\
\text { constructive feedback; } \\
\text { Co-teaching skills }\end{array}$ & $\begin{array}{l}\text { Reduced anxiety; } \\
\text { Supportive \& non-judgemental } \\
\text { learning environment; } \\
\text { Reflection and communication } \\
\text { skills; } \\
\text { Identification of personal } \\
\text { abilities; opportunity to practice } \\
\text { under supportive supervision; } \\
\text { Increased confidence, self- } \\
\text { esteem, and maturity; } \\
\text { Facilitated problem } \\
\text { identification and solving } \\
\text { skills; } \\
\text { Application of new knowledge } \\
\text { in daily tasks; } \\
\text { Benefit from timely \& } \\
\text { constructive feedback, not } \\
\text { criticism; } \\
\text { Development of deep learning }\end{array}$ & $\begin{array}{l}\text { Inspiration for continued } \\
\text { learning; } \\
\text { Role modelling to juniors; } \\
\text { Building of a valued personal, } \\
\text { social, mutual and academic } \\
\text { relationship; } \\
\text { Exposure and visibility; } \\
\text { Protection; } \\
\text { Acceptance; } \\
\text { Affirmation; } \\
\text { Renewed interest for career } \\
\text { growth; } \\
\text { Transformation of the cognitive } \\
\text { and affective domains; } \\
\text { A feeling of coequals \& } \\
\text { openness; } \\
\text { Development of un-defensive } \\
\text { behaviour. }\end{array}$ \\
\hline
\end{tabular}


Apart from the impact on teaching competencies, mentoring was found to create a trusting, supportive, dynamic, respectful, and non-judgmental environment between mentor and mentee (Klinge, 2015). It enabled the participants learn other skills like problem identification and solving, reflection, public speaking, leadership, communication, collaboration, patience, and skills of seeking feedback (Rosenau et al, 2015; Klinge, 2015; Wagner \& Seymour, 2007; Lin, 2007). Successful mentoring develops into a mutual relationship that translates into friendship and subsequent professional growth of the mentor and mentee (Wagner \& Seymour, 2007).

In a study that explored student nurses' and midwives' perception about mentoring, it was found that mentoring increased students' desire to become leaders and enhanced a strong relationship between learner and trainer (Muleya et al., 2015). Students developed reflective and other preferred skills during the period of mentorship (Table 3). Finally, students felt supported when they were given the opportunity to practice after observing their mentor; constructive and timely feedback; and when their own abilities were elucidated (Muleya et al., 2015). Accoring to (Kirkham, 2008),student peer mentoring promotes togetherness, development of deeper learning, and problem-solving skills. It futher enhances commitment to the program and student retention of knowledge.

\section{Negative impact of metoring on nursing and midwifery students and educators}

Time, dual responsibility, workload, personality, and attitude towards the mentorship process came out as the key challenges mentees and mentors experienced (Wagner and Seymour, 2007). Other challenges included students' level of learning, number of students allocated to a mentor, mentor's knowledge about the mentoring process, and tri-or-quadric-collaboration: mentor, mentee, teacher, and coordinator; the team found difficulties in having a common time and agreeing on a common goal since it was not originally stated (Muleya et al., 2015).

\section{Pre-requisites for an effective mentoring program}

Table 4 summarizes some of the pre-requisites for a mentoring program. Establishment of an effective mentoring program requires identification of a relevant model, outlining the components of the program, and clearly defining the context, structure, content, and outcomes (Norwell, Norris, Mrklas, and White,

2017; Nowell, White, Benzies, \& Rosenau, (2017; Kashiwagi, Varkey, \& Cook, 2013; Karcher, Kuperminc, Portwood, Sipe, \& Taylor, 2006).

Table 4. Pre-requisites for an effective mentoring program

\begin{tabular}{|c|c|c|}
\hline Possible mentoring models & $\begin{array}{l}\text { Components/ Elements of a } \\
\text { mentoring program }\end{array}$ & Relevant definitions \\
\hline $\begin{array}{l}\text { Dyad, peer, group, online, } \\
\text { distance, } \quad \text { constellation, } \\
\text { partnership, \& highly relevant } \\
\text { mentoring models. }\end{array}$ & $\begin{array}{l}\text { 1. Formal curriculum with: } \\
\text { - clear purpose \& goals } \\
\text {-selection criteria of mentor } \\
\text { \&mentee } \\
\text {-orientation process } \\
\text {-communication strategy } \\
\text { between mentors \&mentees } \\
\text { - Number \& purpose of } \\
\text { mentor-mentee training } \\
\text { workshops } \\
\text { - Foundational /theoretical } \\
\text { basis of selected model } \\
\text {-Evaluation criteria for } \\
\text { mentor \& mentee } \\
\text { - Socialization \& networking } \\
\text { opportunities } \\
\text { 2. Program funding } \\
\text { 3. Program coordinator }\end{array}$ & $\begin{array}{l}\text { Context } \\
\text { Structure } \\
\text { Content } \\
\text { Outcome } \\
\text { A theoretical model to } \\
\text { clearly state and measure: the } \\
\text { proximal, enabling and distal } \\
\text { outcomes }\end{array}$ \\
\hline
\end{tabular}




\begin{tabular}{|l|l|l|}
\hline & $\begin{array}{l}\text { 4. Administrative support } \\
\text { 5. Monitoring and evaluation } \\
\text { criteria for the entire program } \\
\text { 6. research process }\end{array}$ & \\
\hline
\end{tabular}

\section{Discussion}

Mentoring is key to nursing and midwifery educators since they have the mandate to prepare a future generation of professionals. This section presents an analysis and some interpretations of the results, with a goal of determining whether mentoring can be integrated into nursing training institutions to strengthen the teaching and learning of student nurses and midwives.

\section{Impact of mentoring on nurse and midwifery educator's teaching competences}

This integrative literature review identified tremendous sources of positive impact of mentoring on the nurse and midwifery educators' teaching competencies (Rosenau, Lisella, Clancy, \& Nowell, 2015; Klinge, 2015; Ali, \& Panther, 2008). Senior nurse educators act as role models to the junior. For example, as a senior nurse educator exhibits his/her teaching philosophy, the junior nurse will be motivated to develop a personal philosophy about teaching. Through sharing, caring and nurturing, which are characteristics of mentoring, senior nurse educators pass on pedagogical skills to the junior ones.

According to Campbell (2011), mentoring is a foundational strategy for accomplishing the nurse educator core competences. For example, Competence 1 requires the nurse educator to demonstrate an understanding of the up-to-date educational theories, principles, and models of adult learning (WHO, 2016). Concepts in educational theories require a consistent approach of delivery in a well-articulated, non-judgmental and supportive environment, which the mentoring approach offers. In the same way, some of the tasks within competencies 2, 3, 5, 6 and 7 as outlined by WHO (2016) can effectively be demonstrated or achieved through mentoring, as the literature revealed (Rosenau, Lisella, Clancy, \& Nowell, 2015).

The senior working together with the junior provides exposure, visibility, protection, and acceptance of the new staff. It gives a feeling of affirmation to the new teacher, developing their teaching, and counselling skills (Klinge, 2015). It was futher noted that mentoring creates a feeling of coequals among junior nurse educators (Klinge, 2015). Individuals working together as equals are more likely to be open to one another. This promotes a common understanding between the mentor and mentee, giving room for a closer working relationship, risk taking, and development of undefensive behaviour (Rosenau, Lisella, Clancy, \& Nowell, 2015). These findings can be related to what Hubbard, Foley, and Robert (2010) noted that mentoring tends to produce nurse educators who are commited, caring, and dedicated to producing future generation nurses.

\section{Impact of mentoring to student nurses' and midwives' learning}

Some of the factors that interfere with student nurses 'and midwives' learning include lack of motivation, clinical environment, and shortage of clinical staff and tutors (Mwale \& Kalawa, 2016). Reviewed literature revealed that mentoring creates a supportive and an enabling learning environment, motivates students to practice skills, and enhances retention and job satisfaction (Sawatzky and Enns, 2009; Block et al, 2005). This strengthens the recommendation made by Campbell (2010) to introduce mentorship programs in graduate and undergraduate nursing education for professional development. The benefits of mentoring realized by the student nurses and midwives in the literature review further ascertain that through mentoring, their learning abilities will be enhanced.

\section{Impact of mentoring on educators' and students' personal and career development and social abilities}

According to Wagner \& Seymour (2007) and Chen \& Lou, (2014), mentoring promotes development of mutual relationship, friendship, and subsequent professional growth of the mentor and mentee. This affirms one of the defining characteristics of mentoring outlined by Hodgson and 
Scanlan (2013) as a "relationship based on mutual respect and common goals." The common goals may be related to career, personal, or social development (Lamb, 2005). The impact of mentoring on nurse educators' personal and career development seem to address some of the challenges related to shortage. An established mutual relationship that provides insight into career and personal development motivates a mentee to pursue the career. A study carried out by Flinkman, IsopahkalaBouret, and Salanterä (2013) on young registered nurses' intention to leave the profession and professional turnover in their early career revealed that working environment is one of the contributing factors. This review of literature revealed that a supportive and trusted working environment increases the interest of junior nurses in career development (Muyela et al, 2015; Rosenau et al, 2015; Klinge, 2015; Wagner and Seymour, 2007).

\section{Pre-requisites for an effective mentoring program}

Developing an effective mentoring program requires selection of a relevant mentorship model. Although the reviewed literature did not outline the rationale for selecting a mentoring model, it seems to be influenced by the expected outcome or desired goal. However, dyad and peer mentoring models were mostly used in the reviewed mentoring programs (Norwell, Norris, Mrklas, and White, 2017; Nowell, White, Benzies, \& Rosenau, 2017; Kashiwagi, Varkey, \& Cook, 2013) The reviewed literature revealed varying components of a mentoring program. This can be associated with the different sources of information in relation to professional disciplines, although no specific evidence was found.

Before establishing a mentoring program, it is important to define the context. This means writing clear statements on who will coordinate the program, the level of communication between mentor and mentee (whether mutual, professional, or academic), when to communicate or interact (time), and where to meet (location) (Klinge, 2015; Karcher, et al, 2006). Such details are outlined to ease the process of identifying measuring indicators for the expected outcome. The content is determined by the set goals and are all structured to guide development of a standardized assessment criteria. This is aided by an educational theoretical framework to facilitate problem identification and solving to meet the learner's desired outcome (Klinge, 2015). This means that developing and implementing a mentoring program in a learning institution requires the coordinator to define the characteristics of the likely mentors and mentee in order to select an appropriate theoretical framework to guide the mentoring process. This is because both mentor and mentee undergo a learning process during mentoring. According to Wagner \& Seymour (2007), several failures in the mentor- mentee relationship are attributed to non-commitment to the program, role overload, unrealistic expectations of mentoring, and not valuing the opportunity. Based on evidence found in the literature, further research on mentoring should focus on exploring the rationale for selecting a mentoring model and evaluation of mentoring programs.

\section{Conclusion}

This integrative review of literature coalesces existing evidence on how mentoring impacts nurse educator's teaching competencies and student nurses'/midwives' learning positively. Although there are challenges, they can be overcome if required preparations and principles are followed. Establishing an effective mentoring program should be guided by a relevant mentoring model and the components of a mentoring program, specifically the curriculum, funding, coordination process, administrative support, monitoring, evaluation and research processes.

\section{Implications of the findings to nursing and midwifery practice.}

Nurse and midwifery educators, particularly those in developing countries, should embrace the implementation of mentoring programs to facilitate teaching and learning in their institutions for better professional and health service outcomes.

Nurse and midwifery educators intending to establish a mentoring program should:

- Clearly define the context, structure, and goals (desired outcome) of the program for proper monitoring and evaluation;

- Select a mentoring model basing on the desired outcome of the program; 
DOI: $10.21522 /$ TIJNR.2015.03.02.Art007

ISSN: $2520-3126$

- Encourage mutual selection of mentor and mentee to allow the flow of chemistry yield the expected outcome;

- Introduce mentoring in the early years of students' training for better impact or at the recruitment stage of staff to allow ample time of the mentoring process and better outcomes.

\section{References}

[1].Ali, P. A., \& Panther, W. (2008). Professional Development and the Role of Mentorship. Nursing Standard, 22(42), pp. 35-39.

[2].Block, L. M., Claffey, C., Korow, M. K., Mccaffrey, R., \& Services, H. (2005). The Value of Mentorship within Nursing Organizations. Nursing Forum, 40(4), 134-140.

[3].Chen, C. M., \& Lou, M. F. (2014). The effectiveness and application of mentorship programmes for recently registered nurses: A systematic review. Journal of Nursing Management, 22(4), 433-442. http://doi.org/10.1111/jonm.12102

[4].Hodgson, A. K \& Scanian, J. M. (2013). Mentoring in nursing leadership. Open Journal of Nursing, 3; 389394

[5].Karcher, M. J., Kuperminc, G.P, Portwood, S. G., Sipe, C. L., \& Taylor, A. S. (2006). Mentoring Programs: A Framework to inform program development, Research \& Evaluation. Journal of Community Psychology 34(6), 709-725

[6].Kirkham, R. \& Ringelstein, D. (2008). Student Peer Assisted Mentoring (SPAM): A Conceptual Framework, e-JBEST 2(2), 39-49.

[7].Klinge, C. M. (2015). A conceptual framework for mentoring in a learning organization. Journal of Adult Learning, 26(4);

[8].Lin, P. (2007). The effect of a mentoring development program on mentors' conceptualizing mathematics teaching and mentoring, 3, 201-208.

[9].Muleya, C. M., Marshall, J., \& Ashwin, C. (2015). Nursing and Midwifery Students' Perception and Experiences of Mentorship: A Systematic Review. Open Journal of Nursing, (June), 571-586. http://doi.org/10.4236/ojn.2015.56061

[10]. Nowell, L., White, D. E., Benzies, K., \& Rosenau, P. (2017). Exploring mentorship programs and components in nursing academia. Journal of Nursing Education and Practice, 7(9); 42-53

[11]. Nowell, L., White, D. E., Mrklas, K., \& Norris, J. M. (2015). Mentorship in nursing academia: a systematic review protocol, 1-9. http://doi.org/10.1186/s13643-015-0007-5

[12]. Learning and Professional Developmental (2011). Establishing a mentoring program framework. Ohio Das, PM. R etrieved August 2017 from: http://www.das.ohio.gov/PJR.PDF?CER=2012-08-15-142823083RCN. (2015). RCN Mentorship Project 2015.

[13]. Sawatzky, J., Enns, C. L. (2009). (1) A Mentoring Needs Assessment_ Validation _ Jo-ann Sawatzky Academia.pdf. Journal of Professional Nursing, 25(3), 145-150.

[14]. Scotland, N. E. (2007). National Approach to Mentor Preparation for Nurses and Midwives.

[15]. Wagner, A. L., \& Seymour, M. (2007). A Model of Caring Mentorship for Nursing. Journal for Nurses in Staff Development, 23(5), 201-211.

[16]. WHO (2016). Nurse Educator Core Competencies. 